\title{
Discrepancies between clinicians and rural healthcare workers regarding referral procedures based on blood pressure measurements
}

\author{
Ibrahim Mohedas a ${ }^{\text {, Frank W.J. Anderson }}{ }^{\text {b }}$, Joseph Adomako ${ }^{c}$, Kathleen H. Sienko ${ }^{\text {ad, }, *}$ \\ a Department of Mechanical Engineering, University of Michigan, Ann Arbor, USA \\ ${ }^{\mathrm{b}}$ Department of Obstetrics and Gynecology, University of Michigan, Ann Arbor, USA \\ c Ghana Health Service, District Health Directorate, Kuntanase, Ghana \\ d Department of Biomedical Engineering, University of Michigan, Ann Arbor, USA
}

\section{A R T I C L E I N F O}

\section{Article history:}

Received 5 April 2013

Received in revised form 13 June 2013

Accepted 23 August 2013

\section{Keywords:}

Blood pressure

Community healthcare workers

Hypertension

Low-resource countries

Maternal health

Pre-eclampsia

Referral network

Hypertensive disorders of pregnancy are the third most common cause of maternal mortality worldwide, and the proportion of deaths resulting from these disorders is increasing [1,2]. Proper management begins with correct diagnosis and appropriate referral decisions. Within maternity referral networks in low-resource countries, rural healthcare workers are the first to identify hypertension, which requires accurate equipment and proper measurement technique.

The aim of the present study was to assess whether referral procedures based on blood pressure measurements were consistent throughout a maternity referral network.

Seventy-five semi-structured interviews were performed at healthcare centers-teaching hospital $(n=1)$, district hospitals $(\mathrm{n}=10)$, health clinics $(\mathrm{n}=11)$, and community health posts $(\mathrm{n}=8)$-within a convenience sample of 9 districts in Ghana. Participants were asked to define the blood pressure measurement that would be considered high and warrant treatment and/or referral. Participant groups included obstetricians and physicians, midwives/nurses, and community health workers (CHWs). The study was approved by institutional review boards at the University of Michigan and Ghana Health Service, and each participant gave informed consent before the study began.

Data analysis was performed using SPSS version 19 (IBM, Armonk, NY, USA). $P<0.05$ was considered to be statistically significant.

A consistent blood pressure threshold for treatment and/or referral was not identified among the groups (Fig. 1). Nearly all obstetricians and physicians noted $140 / 90 \mathrm{~mm} \mathrm{Hg}$ as the threshold for referral, consistent with the definition of hypertension and the Ghana Health Service's referral criteria and associated protocols (i.e. patients are referred when either their systolic or their diastolic pressure is equal to or exceeds 140 or $90 \mathrm{~mm} \mathrm{Hg}$, respectively) [3,4]. Midwives/nurses and CHWs reported more variable thresholds. When comparing group variances, folded $F$ tests revealed statistically significant differences between all groups $(P<0.05)$. In addition, there were differences in variance between urban (teaching/district hospitals) and rural (health clinics/community health posts) healthcare centers with regard to

\footnotetext{
* Corresponding author at: University of Michigan, 2350 Hayward Street, 1109 G.G. Brown, Ann Arbor, MI 48109, USA. Tel.: + 1734647 8249; fax: +1 7346479379.

E-mail address: sienko@umich.edu (K.H. Sienko).
}

systolic thresholds $(P<0.05)$. Only 9 participants reported that they also considered a rise in blood pressure from pre-pregnancy to be an indication to treat/refer.

The present study found inconsistent referral procedures among participants in rural settings. Thirteen participants set referral thresholds below 140/90 $\mathrm{mm} \mathrm{Hg}$-possibly leading to normotensive women being unnecessarily referred to higher-level facilities, placing an unnecessary burden on pregnant women, and leading to reduced levels of confidence in the referring providers. Nineteen participants set referral thresholds above $140 / 90 \mathrm{~mm} \mathrm{Hg}$-possibly leading to hypertensive women not being referred to the proper facility at the appropriate time and to the worsening of symptoms.
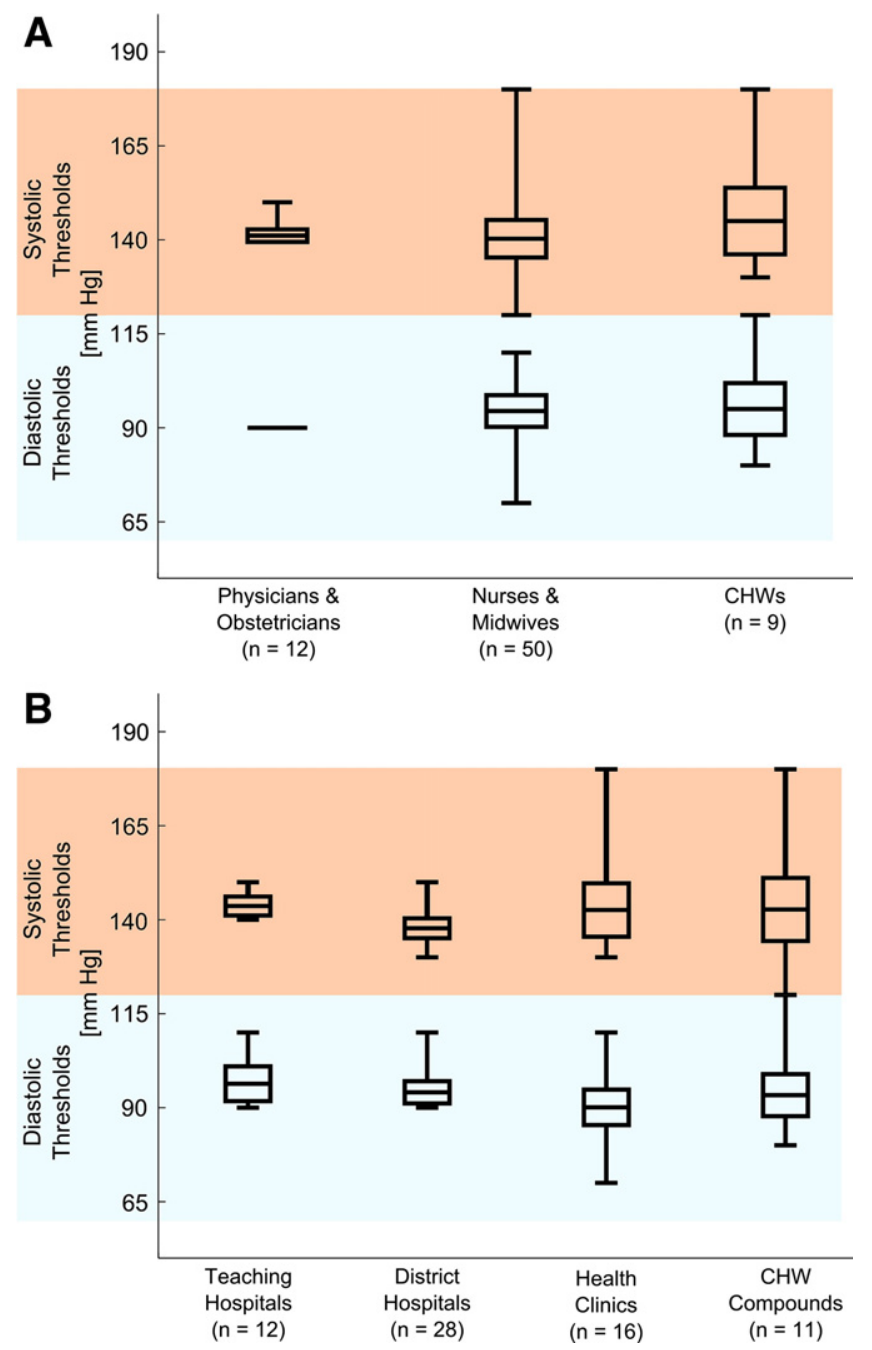

Fig. 1. Range, mean, and standard deviation of systolic and diastolic thresholds reported by healthcare participants. A. Systolic and diastolic thresholds reported by healthcare participant group. B. Systolic and diastolic thresholds reported by healthcare center. Range is indicated by the whiskers, standard deviation by the rectangles, and mean by the solid lines within the rectangles. 
The inconsistent referral practices found among healthcare workers in rural areas highlight the need for simple and clear criteria and educational materials/training methods that reduce these inconsistencies. Furthermore, blood pressure equipment and accompanying measurement techniques tailored to the needs of rural healthcare workers may facilitate the identification of hypertension.

\section{Conflict of interest}

The authors have no conflicts of interest.

\section{References}

[1] Lopez AD, Mathers CD, Ezzati M, Jamison DT, Murray CJL. Global Burden of Disease and Risk Factors. New York, NY: Oxford University Press, World Bank Publications; 2006.

[2] Duley L. The global impact of pre-eclampsia and eclampsia. Semin Perinatol 2009;33(3):130-7.

[3] Messerli FH. Definition of Hypertension. In: Messerli FH, editor. Clinician's Manual: Treatment of Hypertension. 3rd ed. New York, NY: Springer; 2011. p. 1-2.

[4] Ministry of Health, Ghana Health Service. Guidelines for the establishment of Screening Services in Regional Hospitals. http://www.ghanahealthservice.org/includes/upload/ publications/Hospital\%20Screening\%20Services\%20guidelines\%202.1.pdf. Published 2011. Accessed June 13, 2013.

\title{
Maternal and perinatal outcomes among women with eclampsia admitted to a tertiary care hospital in Hyderabad, Pakistan
}

\author{
Naushaba Rizwan ${ }^{\text {a,* }}$, Sumera Rauf ${ }^{\text {a }}$, Syed Farhan-Uddin ${ }^{\text {b }}$ \\ a Department of Obstetrics and Gynaecology, Liaquat University of Medical and Health Sciences, Jamshoro, Pakistan \\ b Department of Physiology, Liaquat University of Medical and Health Sciences, Jamshoro, Pakistan
}

\section{A R T I C L E I N F O}

\section{Article history:}

Received 17 March 2013

Received in revised form 7 June 2013

Accepted 28 August 2013

\section{Keywords:}

Eclampsia

Maternal

Morbidity

Mortality

Perinatal

Eclampsia continues to be a problem, particularly in low-resource countries such as Pakistan where it contributes significantly to high maternal and perinatal morbidity and mortality. Eclampsia is responsible for approximately $12 \%$ of all global maternal deaths and $16 \%-31 \%$ of perinatal deaths $[1,2]$.

To analyze the incidence of eclampsia in Hyderabad, Pakistan, and to identify the maternal and perinatal outcomes of patients with eclampsia treated at a tertiary care hospital, a descriptive cross-sectional study of all women presenting with eclampsia at Liaquat University Hospital was conducted between June 1, 2010, and February 28, 2011. Ethics committee approval and appropriate informed consent were obtained.

Information was collected on demographic data, clinical findings, laboratory results, and patient and newborn outcomes. All data were analyzed using SPSS version 10 (IBM, Armonk, NY, USA).

Among the 6526 deliveries during the study period, 80 women presented with eclampsia (incidence of $1.2 \%$ ). Of the patients with eclampsia, however, only $45.0 \%(n=36)$ and $25.0 \%(n=20)$ were screened for blood pressure and proteinuria, respectively. The age range was $16-40$ years, with the majority of women younger than 20 (47.5\%; $\mathrm{n}=38) ; 61.3 \%(\mathrm{n}=49)$ were primiparous and $38.8 \%(\mathrm{n}=31)$ were multiparous.

\footnotetext{
* Corresponding author at: House No. 72, Block-D, Latifabad No. 10, Hyderabad 71000, Pakistan. Tel.: + 9222 3401558; fax: +92229213306

E-mail address: naushabarizwansyed@yahoo.com (N. Rizwan).
}

The main factors contributing to maternal morbidity were placental abruption (13.8\%; $\mathrm{n}=9$ ), pulmonary edema $(11.3 \% ; \mathrm{n}=9)$, maternal stroke ( $8.8 \% ; n=7)$, HELLP syndrome $(5.0 \% ; n=4)$, disseminated intravascular coagulopathy $(5.0 \% ; \mathrm{n}=4)$, and acute renal failure $(11.3 \% ; n=9)$ (Table 1$)$. There were $6(7.5 \%)$ maternal deaths and $17(21.3 \%)$ perinatal deaths. Forty-eight infants had low birth weight.

Optimal strategies in the care of women with pre-eclampsia have not been fully elucidated. The incidence of eclampsia in high-resource countries is 1 per 2000 to 5 per 1000 deliveries [3,4], while in Pakistan it ranges from $0.5 \%$ to $4 \%$ [5]. In addition to maternal morbidity and mortality, eclampsia accounts for a major proportion of perinatal mortality, which is estimated to be 68-474 per 1000 deliveries in Pakistan [6-8]. The maternal mortality rate associated with eclampsia varies worldwide, from $1.8 \%$ in the UK to $43.1 \%$ in Nigeria $[9,10]$. In high-resource countries, the incidence of eclampsia has fallen considerably. In most cases, however, the onset of pre-eclampsia is insidious, and pathologic changes occur weeks before clinically detectable hypertension and proteinuria. Therefore, the challenge is to balance the timing of delivery of patients with pre-eclampsia before the onset of eclampsia.

\section{Conflict of interest}

The authors have no conflicts of interest.

Table 1

Maternal and perinatal outcome $(\mathrm{n}=80)$.

\begin{tabular}{lc}
\hline Outcome & Number (percentage) \\
\hline Maternal & \\
Placental abruption & $11(13.8)$ \\
Pulmonary edema & $9(11.3)$ \\
Acute renal failure & $9(11.3)$ \\
HELLP syndrome & $4(5.0)$ \\
Disseminated intravascular coagulation & $4(5.0)$ \\
Maternal stroke & $6(7.5)$ \\
Perinatal & \\
Stillbirth & $10(12.5)$ \\
Early neonatal death & $7(8.8)$ \\
Alive & $63(78.8)$ \\
\hline
\end{tabular}

